\title{
Non-T Non-B CALLA Positive Childhood Acute Lymphoblastic Leukemia
}

National Cancer Institute

\section{Source}

National Cancer Institute. Non-T Non-B CALLA Positive Childhood Acute Lymphoblastic Leukemia. NCI Thesaurus. Code C9141.

A non- $T$, non- $B$, acute lymphoblastic leukemia in which the lymphoblasts are positive for the common acute lymphoblastic leukemia antigen (CALLA) occurring in children. 